\title{
Qualidade de Vida no Trabalho: Um estudo de Caso na Célula de Desenvolvimento de Pessoas da Gerência Regional de Educação do Sertão do Médio São Francisco \\ Taciana Rita Santos Souza ${ }^{1}$; Clécio da Silva Souza ${ }^{2}$; Milka Alves Correia Barbosa ${ }^{3}$
}

\begin{abstract}
Resumo: Os indivíduos passam parcela considerável do seu tempo no ambiente de trabalho e se observa que, embora existam organizações que voltam a atenção para a Qualidade de Vida no Trabalho, também encontramos aquelas que estão preocupadas apenas com lucro e tratam seus funcionários como recursos financeiros ou materiais, deixando de reconhecê-los como potenciais talentos. Dentro deste contexto, realizou-se um estudo de caso, de natureza exploratória, com o objetivo de aprofundar e detalhar informações sobre a percepção dos colaboradores (servidores e contratados) lotados na Célula de Desenvolvimento de Pessoas da Gerência Regional de Educação (GRE) de Petrolina, enfocando a Qualidade de Vida no Trabalho. A investigação utilizou o modelo desenvolvido por Fernandes (1996), que leva em consideração nove dimensões. Para coleta de dados foi elaborado questionário, respondido por 15 colaboradores. Ressalta-se, que a melhoria dos fatores causadores de mal-estar, não depende apenas da GRE, mas principalmente da alta administração do órgão.
\end{abstract}

Palavras-chave: Qualidade de vida no trabalho. Pessoas. Percepção. Satisfação. Eficiência Organizacional.

\section{At Work Life Quality: A Case Study in People Development Cell Management Education Regional middle São Francisco Sertão}

\begin{abstract}
Individuals spend considerable portion of their time in the workplace and notes that while there are organizations turn their attention to the Quality of Life at Work, we also find those who are concerned only with profit and treat their employees as financial or material resources, failing to recognize them as potential talents. Within this context, there was a case study, exploratory, aiming to deepen and detail information on the perception of employees (servers and contractors) crowded in People Development Cell Regional Education Management (GRE) of Petrolina, focusing on Quality of Life at Work. The research used the model developed by Fernandes (1996), which takes into account nine dimensions. For data collection was prepared questionnaire answered by 15 employees. It is noteworthy that the improvement of the causative factors of malaise, depends not only on GRE, but especially senior management agency.
\end{abstract}

Keywords: Quality of life at work. People. Perception. Satisfaction. Organizational efficiency

\section{Introdução}

O trabalho é um dos importantes pilares da forma como a sociedade está organizada, considerando-se que os indivíduos passam boa parte de suas vidas se preparando para o momento em que se tornarão agentes ativos do mercado de trabalho. De fato, o paradigma da vida social moderna revela a importância do trabalho como fonte de riqueza, identidade e desenvolvimento do indivíduo (COSTA, 2010).

\footnotetext{
${ }^{1}$ Pós-graduanda em Gestão Pública pela Universidade Federal do Vale do São Francisco

${ }^{2}$ Pós-graduando em Gestão Pública pela Universidade Federal do Vale do São Francisco.

${ }^{3}$ Doutora e Mestre em Administração pelo PROPAD/Universidade Federal de Pernambuco; professora Adjunta na Universidade Federal de Alagoas, campus de Arapiraca/Curso de administração. E-mail: milka.barbosa@univasf.edu.br.
} 
Id on Line Revista Multidisciplinar e de Psicoloqia

Id on Line Revista Multidisciplinar e de Psicologia

No entanto, a mesma autora afirma que o trabalho na sociedade contemporânea se modificou radicalmente com o advento da tecnologia, parecendo comandar a ação humana e impactando a relação homem-trabalho, resultando, assim, em um processo de desumanização do sistema produtivo. Sendo assim, as condições de trabalho, desde as formas de gestão até a estruturação da organização, não raro afetam a motivação e o desempenho do trabalhador.

Assumindo-se a representatividade do trabalho para a vida das pessoas, surge a necessidade $\mathrm{e}$ a importância de estudos sobre a Qualidade de Vida no Trabalho (QVT). Nesse sentido, observa-se que, apesar de muitas organizações se preocuparem com a qualidade de vida dos seus colaboradores, ainda existem aquelas que priorizam somente o lucro e veem as pessoas apenas como recursos financeiros ou materiais, deixando de reconhecê-las como potenciais talentos. Em tais organizações, percebe-se que não há a devida preocupação com a qualidade de vida dos funcionários, mantendo-se a visão do homo economicus, que surgiu com Taylor e Fayol, durante o movimento da administração científica (MARRAS, 2011).

Diante da crescente preocupação com a humanização do trabalho, Medeiros e Ferreira (2011) afirmam que, do ponto de vista conceitual, a literatura apresenta uma variedade de conceitos para QVT com diferentes visões sobre o trabalhador e o trabalho e enfoques de gestão do trabalho. Nesse sentido, o trabalho de Fernandes (1996) já destacava que a QVT busca conciliar não apenas os interesses dos indivíduos, mas também das organizações, pois, segundo a autora, melhora a satisfação do trabalhador e a produtividade da empresa, podendo ser entendida como uma gestão dinâmica e contingencial de elementos físicos, tecnológicos e sociopsicológicos que exercem influência sobre a cultura e o clima organizacional.

No âmbito das organizações públicas, observa-se que a QVT merece atenção especial em decorrência do tipo peculiar de configuração organizacional, em geral burocrática e fortemente orientada por dispositivos legais de controle da administração pública, limitando em diversas situações a atuação do gestor público, principalmente no que se refere à implementação de novos programas ou políticas de gestão.

Considerando esse contexto, o presente artigo teve como objetivo analisar a percepção dos colaboradores lotados na Célula de Desenvolvimento de Pessoas (CDP) da Gerência Regional de Educação de Petrolina sobre a QVT. Para tanto, foi utilizado o modelo proposto por Fernandes (1996), que leva em consideração nove dimensões por meio das quais busca-se a eficiência organizacional, com resultados positivos tanto para o trabalhador quanto para a organização.

$\mathrm{O}$ interesse em desenvolver este estudo na CDP justifica-se pelo entendimento de que essa instituição deve preocupar-se com a QVT de seus colaboradores, já que ele é responsável por promover o desenvolvimento de pessoas em consonância com as diretrizes e políticas educacionais do 
Id on Line Revista Multidisciplinar e de Psicologia

Id on Line Revista Multidisciplinar e de Psicologia

Estado e aplicar as normas de administração de pessoal, garantindo o seu cumprimento na respectiva jurisdição.

Este artigo está estruturado em três seções, além desta introdução. A segunda seção traz o referencial teórico que deu suporte à pesquisa. Na terceira seção, são apresentados os procedimentos metodológicos utilizados na elaboração deste estudo, enquanto na quarta foram analisados os dados coletados. Por fim, apresentam-se algumas reflexões, contendo, inclusive, sugestões para intervenção na organização estudada.

\section{Gestão de pessoas: conceitos, modelos e evolução}

Em tempos de constantes mudanças e incertezas, atributos como agilidade, flexibilidade e criatividade são indispensáveis à organização e podem ser alcançados por meio de uma equipe de trabalho participativa e alinhada com os objetivos organizacionais.

Para atender às exigências desse novo ambiente, é imprescindível que as organizações despertem para o desafio de gerir pessoas inseridas em um cenário amplamente diverso, considerando suas individualidades e competências, visando ao desenvolvimento humano dentro do ambiente de trabalho. Segundo Fischer (2002), o modelo de gestão de pessoas possibilita à organização desenvolver uma forma de atuação sobre o comportamento humano e que é influenciado por fatores internos e externos à própria organização, diferenciando-se de acordo com o contexto histórico e setorial.

Mais recentemente, Dutra (2012, p. 17) definiu gestão de pessoas (GP) como "o conjunto de políticas e práticas que permitem a conciliação de expectativas entre a organização e as pessoas para que ambas possam realizá-las ao longo do tempo". Disso, percebe-se que o desenvolvimento de políticas e ações articuladas nesse campo pode suprir os anseios dos indivíduos e da organização, construindo um pilar da relação de produção.

Dada a importância da gestão de pessoas para as organizações, é importante conhecer o processo histórico inerente à sua origem e à sua evolução, bem como, as formas que ela tem se apresentado na perspectiva de alcançar a excelência organizacional. Sobre esse aspecto, foi no século XIX que surgiram os primeiros registros ligados à gestão de pessoas e somente no século XX que ocorreu a estruturação da área de GP (DUTRA, 2012).

Nesse sentido, Gil (2007) apresenta a trajetória evolutiva da GP a partir do modelo de Administração Científica, no qual aquela era praticamente inexistente, já que tal modelo restringia o desenvolvimento do indivíduo, submetendo-o a um trabalho degradante. Já com estudos de Elton Mayo, em 1927, a escola das relações humanas considerava a influência de fatores psicológicos e sociais na produtividade e no comportamento humano no trabalho. 
Id on Line Revista Multidisciplinar e de Psicologia

Id on Line Revista Multidisciplinar e de Psicologia

Após o final da Segunda Guerra Mundial (1939-1945), houve significativas mudanças na administração de pessoal, de modo que as entidades representativas dos trabalhadores ganharam forças em suas lutas de classe e as empresas passaram a preocupar-se com a concessão de benefícios e as condições de trabalho.

Ainda em relação a esse caminho percorrido pela GP, Gil (2007) aponta a fase da Administração de Recursos Humanos iniciada em 1960, com o advento da Teoria Geral dos Sistemas, que se pauta em conceitos como a interdependência das partes, multidisciplinaridade, participação e abertura. A partir da década de 1990, as empresas foram impactadas por questionamentos quanto ao modo como estavam conduzindo a administração de recursos humanos, dados os desafios, tanto de ordem ambiental quanto organizacional, ocasionados por diversos fatores, a exemplo da globalização da economia, inovações tecnológicas, etc.

Como resultado, gerou-se a demanda das organizações tratarem as pessoas como parceiros, já que são elas as responsáveis por todo o progresso organizacional, tendo em vista serem os detentores de conhecimento e habilidades. Diante dessa nova visão, surge o atual enfoque da gestão de pessoas, pautada na participação dos indivíduos nas tomadas de decisões e na utilização dos seus talentos, proporcionando, assim, o desenvolvimento do indivíduo e da organização.

Para Fischer (2002), os critérios articuladores dos elementos que compõem um modelo de gestão diferenciam-no tempo e, por isso, o autor classifica as abordagens sobre a gestão de pessoas em quatro categorias principais, a saber:

- Gestão de pessoas como departamento pessoal: Os funcionários eram gerenciados como custo e por isso buscava-se a máxima eficiência do seu trabalho pautada em conceitos de produtividade, recompensa e eficiência de custos;

- Gestão de pessoas como gestão do comportamento humano: Interferência da psicologia nas organizações, apoiando na compreensão do comportamento das pessoas. Surge também nessa época a escola de relações humanas, adotando a motivação e a liderança como fatores preponderantes desse modelo;

- Modelo estratégico de gestão de pessoas: Caráter estratégico da GP, ou seja, não basta ter indivíduos motivados, satisfeitos e bem atendidos, é necessário definir políticas e práticas de RH alinhadas com as estratégias da organização;

- Modelo de gestão de pessoas articulado por competências: A gestão de pessoas está estritamente ligada à temas como vantagem competitiva, reengenharia e competências.

Corroborando a discussão de Fischer (2002), para Vergara (2011), a tradicional pirâmide hierárquica enfraqueceu dando lugar às novas estruturas organizacionais, a exemplo das estruturas em rede, aproximando a empresa de seu ambiente externo e tornando-a ao mesmo tempo mais integrada 
Id on Line Revista Multidisciplinar e de Psicologia

Id on Line Revista Multidisciplinar e de Psicologia

internamente. Com isso, espera-se que a atuação diária dos indivíduos na organização seja orientada pela visão e ação estratégica com vistas a alcançar os resultados planejados (VERGARA, 2011).

Reconhecendo que as organizações são detentoras de suas particularidades e que apresentam características compatíveis com o seu desenho organizacional, Bergue (2010, p. 18) apresenta uma definição específica para gestão de pessoas no setor público, conceituando-a como um "esforço orientado para o suprimento, a manutenção e o desenvolvimento de pessoas nas organizações públicas, em conformidade com os ditames constitucionais e legais, observadas as necessidades e condições do ambiente em que se inserem".

O autor ainda faz menção ao processo evolutivo da GP no setor público, associando-o a três momentos diferentes da administração em relação às pessoas: administração de pessoal, administração de recursos humanos e administração de pessoas. No primeiro momento, verifica-se uma atuação voltada para aspectos básicos da vida funcional dos servidores, como folha de pagamento e ficha funcional. No segundo, percebe-se certo avanço no que tange aos indivíduos dentro das organizações, pois, embora carregado de traços mecanicistas, é o momento que surge um modo de análise sistêmica das organizações.

Por fim, no terceiro momento, também denominado gestão de pessoas, os indivíduos passam ser vistos como o recurso de maior valor para as organizações, pois são elas as responsáveis por gerar riqueza.

Importa, pois, ressaltar que a gestão de pessoas no setor público - se comparada com as organizações da iniciativa privada - encontra-se bastante defasada, principalmente em organizações da esfera municipal, as quais, em sua grande maioria, permanecem desempenhando apenas as funções elencadas no primeiro estágio evolutivo acima mencionado (BERGUE, 2010).

Sendo assim, as instituições, sejam elas públicas ou privadas, precisam se preocupar com a qualidade de vida dos seus funcionários, pois, se eles não têm saúde e motivação, o bem-estar organizacional será afetado. Daí, portanto, a importância de se analisar como a QVT está sendo utilizada para motivar as pessoas e assegurar bons resultados para a organização, o que será tratado na próxima seção.

\section{Qualidade de Vida no Trabalho (QVT)}

Foi durante a Revolução Industrial que o trabalho artesanal foi gradativamente substituído pelo fabril. Com o aumento dos centros urbanos, em decorrência da população oriunda dos feudos, houve um acúmulo de mão de obra e estas pessoas acabam se vendo obrigadas a vender sua força de trabalho aos donos de capital, que as submetiam a condições degradantes de trabalho (ARENDT, 
Id on Line Revista Multidisciplinar e de Psicologia

Id on Line Revista Multidisciplinar e de Psicologia

2003). Nesse período, não havia uma preocupação com a qualidade de vida dos trabalhadores, pois as pessoas eram vistas apenas como parte do processo produtivo.

A origem dos estudos sobre a Qualidade de Vida no Trabalho (QVT) pode ser associada ao grupo de pesquisadores dirigidos por Eric Trist, no Tavistock Institute, em Londres, que desenvolveram estudos específicos voltados para uma abordagem sóciotécnica da relação indivíduotrabalho-organização do trabalho, visando promover a satisfação dos trabalhadores e evitar, assim, que a vida deles fosse se deteriorando. Contudo, é na década de 1970 que o termo Qualidade de Vida no Trabalho (QVT), utilizado por Louis Davis, surge como um conceito (FERNANDES, 1996).

Ao definir QVT, Limongi-França (1996) caracteriza-a como um conjunto de ações que uma empresa utiliza para inserir melhorias e inovações gerenciais, tecnológicas e estruturais no ambiente de trabalho.

Pode-se identificar duas posições antagônicas da QVT: “de um lado, a reivindicação dos empregados quanto ao bem-estar e a satisfação no trabalho; e do outro, o interesse das organizações quanto aos seus efeitos potencializadores sobre a produtividade e a qualidade" (CHIAVENATO, 2004, p. 448).

Desse modo, reconhece-se que não é fácil conciliar os interesses organizacionais e individuais, pois a organização volta a atenção para o seu próprio desenvolvimento em busca do alcance dos seus objetivos organizacionais, enquanto os trabalhadores almejam um ambiente que desenvolva um sentimento de pertencimento, fazendo com que eles sintam prazer em ocupar os espaços que lhes são destinados, e expressem satisfação em desenvolver as tarefas que lhe são atribuídas. Ainda assim, embora os desejos dos funcionários e da organização sejam supostamente diferentes, destaca-se que programas de QVT podem contribuir para a aproximação entre os interesses organizacionais e dos trabalhadores, pois propiciam implicações favoráveis não apenas para o âmbito pessoal, mas também para o êxito organizacional. Assim, embora existam diferentes enfoques para tratar sobre a QVT, a principal meta do programa é alinhar os interesses dos funcionários com os da organização; portanto, na proporção em que se melhoram os níveis de satisfação dos trabalhadores, eleva-se a produção da empresa (FERNANDES, 1996).

Dentre os modelos de QVT, destacam-se os de Nadler e Lawler, o de Hackman e Oldhan e o de Walton (CHIAVENATO, 2004). O modelo de QVT de Nadler e Lawler (1983) está estruturado em quatro aspectos: envolvimento dos funcionários nas decisões; reestruturação do trabalho por meio do enriquecimento de tarefas; inovação nos sistemas de recompensas; melhorarias nas condições do ambiente de trabalho. Por conseguinte, à proporção que estes aspectos são aplicados, verifica-se uma melhoria na QVT.

Já para Hackman e Oldham (1975), as dimensões do cargo conduzem efeitos psicológicos que exercem influência sobre os resultados pessoais e de trabalho e impactam na QVT. Esses autores destacam as seguintes dimensões do cargo: a) variação nas habilidades; b) identidade da tarefa; c) 
Id on Line Revista Multidisciplinar e de Psicologia

Id on Line Revista Multidisciplinar e de Psicologia

significado da tarefa; d) autonomia; e) retroação do próprio trabalho; f) retroação extrínseca; g) interrelacionamento (CHIAVENATO, 2004, p. 450). Paiva e Marques (1999) destacam que a concepção de Hackman e Oldham sobre a QVT fundamenta-se em características objetivas das tarefas que são realizadas dentro da organização.

O modelo proposto por Walton (1975), conforme observa Chiavenato (2004), é composto por oito fatores que afetam a QVT: compensação justa e adequada; condições de segurança e saúde no trabalho; utilização e desenvolvimento de capacidades; oportunidades de crescimento contínuo e segurança; integração social na organização; constitucionalismo; trabalho e espaço total de vida; relevância social da vida no trabalho. Esse modelo volta-se à humanização do ambiente de trabalho, procurando evitar uma volta às velhas práticas de trabalho, ao atentar para os efeitos da automação sobre a qualidade de vida dos trabalhadores (FERNANDES, 1996).

Para o presente estudo, será considerado o modelo proposto por Fernandes (1996), denominado Auditoria Operacional de Recursos. Nesse modelo, a QVT caracteriza-se por uma gestão dinâmica e contingencial, em que os fatores físicos, tecnológicos, sociais e psicológicos interferem na cultura e no clima da organização e afetam diretamente a produção e o bem-estar do trabalhador.

O modelo proposto por Fernandes (1996) é composto por nove dimensões, quais sejam:

1. Condições de trabalho: visa analisar se o funcionário está satisfeito com o ambiente físico de trabalho em que ele desempenha suas funções, a partir da iluminação adequada, temperatura, ruído, ergonomia e limpeza.

2. Compensação: procura verificar o grau de satisfação dos funcionários no que diz respeito ao plano de cargos e carreira, salários e benefícios.

3. Moral: verifica de que forma as ações gerenciais voltadas para os aspectos de motivação e moral do profissional afetam a identificação com a tarefa, o reconhecimento e as relações interpessoais.

4. Imagem da organização: visa examinar a imagem externa da organização e identificação com a organização.

5. Saúde: objetiva abordar as ações que são desenvolvidas pela organização no que diz respeito à saúde analisando a segurança no trabalho, saúde ocupacional, assistência para a família do funcionário e assistência para o funcionário.

6. Organização do trabalho: tem por objetivo avaliar a estruturação das novas formas de trabalho. Assim, para isso é preciso considerar as metodologias de trabalho, tarefas realizadas, ritmo e grupos de trabalho.

7. Participação: examina a percepção do funcionário quanto a sua aceitação e o envolvimento com as ações que são empreendidas, de modo que é analisado a oportunidade de contribuir com ideias criativas e o recebimento de programas de treinamento e capacitação. 
Id on Line Revista Multidisciplinar e de Psicoloqia

Id on Line Revista Multidisciplinar e de Psicologia

8. Comunicação: tem por objetivo investigar a eficácia das comunicações em todos os níveis, analisando-se o nível de informação quanto ao fluxo de informações (entre os servidores), fluxo de informações (chefe-subordinado) e conhecimento das metas da organização.

9. Relação chefe-subordinado: mede o grau de satisfação ou insatisfação com esta relação. Desse modo, devem ser considerados os seguintes elementos para avaliação: feedback, respeito, cordialidade, igualdade de tratamento e orientação técnica.

Cabe, aqui, esclarecer que a escolha do modelo de Fernandes (1996) como método de análise justifica-se pelo fato de este ter por objetivo a conciliação dos interesses da organização e dos indivíduos, possibilitando verificar a percepção dos funcionários em relação à QVT, identificando os aspectos positivos e aqueles que precisam ser desenvolvidos ou melhorados pela Gerência Regional de Educação (GRE) do Sertão do Médio São Francisco nesse quesito.

Acreditando-se que há especificidades nas organizações públicas, a próxima seção ocupa-se de abordar a QVT nesse ambiente organizacional.

\section{QVT em organizações públicas}

Observa-se que existem diversos estudos voltados para a QTV no Brasil, com destaque para os de Fernandes (1996), Silva e Marchi (1997), Limongi-França (1996) e Arellano (2007). Segundo Ferreira et al (2009), foi a partir da década de 1970 que se intensificaram os estudos voltados para a QVT, em especial, nas grandes empresas.

Contudo, quando se trata desse tema na administração pública, Sá et al (2007) afirmam que a QVT ainda é um assunto pouco explorado na prática gerencial das organizações públicas. Ou seja, não obstante o tema ter recebido atenção nos últimos anos, ainda é permeado de algumas incertezas no que diz respeito ao âmbito e às responsabilidades pela sua gestão.

De fato, as mudanças nas formas de estruturação do trabalho e as inovações tecnológicas vêm impondo novos modelos de gestão para as organizações públicas e privadas, demandando dos gestores o repensar as práticas organizacionais com vistas ao enfrentamento de desafios (FERREIRA et al, 2009). Dentro deste contexto, é importante discutir acerca das mudanças ocorridas na Administração Pública no Brasil, entendendo de que forma elas contribuíram ou não para a implantação da QVT em organizações públicas.

O trabalho de Amorim (2010) alertava para o fato de que ainda não se verificam muitas ações voltadas para a estruturação e implantação de programas de QVT no serviço público, sendo que uma das principais dificuldades enfrentadas está no fato de o gestor público encontrar-se cercado por elementos normativos da instituição, como restrições nos valores orçamentários, licitação e estruturação dos cargos e carreiras. Esses aspectos fazem com que aumente seu poder vinculado, reduza consequentemente o seu poder discricionário, limitando a tomada de decisões e dificultando o desenvolvimento da gestão de acordo com as necessidades institucionais. 
Id on Line Revista Multidisciplinar e de Psicologia

Id on Line Revista Multidisciplinar e de Psicologia

Além desses fatores, vale salientar que a maioria das organizações públicas ainda apresenta a burocracia como seu modelo organizacional. Nessa ótica, Robbins et al (2010) ressaltam que a obsessão em obedecer às regras, a padronização somada à elevada formalização e as decisões centralizadas, dentre outras especificidades, acabam fazendo com que as metas das unidades se sobreponham às da organização como um todo.

Com base nisso, é possível argumentar que as organizações públicas precisam ser estruturadas de modo que haja uma preocupação com a saúde do servidor, evitando, assim, insatisfação com o ambiente de trabalho, redução da produtividade e mau atendimento ao usuário do serviço público.

Nesse sentido, concorda-se com Amorim (2010, p. 38) de que "a aplicação da QVT na administração pública é capaz de preencher uma lacuna verificada, ao longo dos anos, no nível de tratamento oferecido ao servidor público relativa à valorização do seu trabalho e preocupação com o seu bem-estar e o de sua família".

Sendo assim, à medida que as instituições públicas, por meio dos seus gestores, despertarem para a relevância da QVT e passarem a implementar ou melhorar as políticas desta, será possível vislumbrar melhorias no bem-estar dos servidores, resultando em atendimento de qualidade e contribuindo positivamente para a imagem da organização pública junto à sociedade.

Apresentados os temas que deram suporte ao estudo, apresentam-se, a seguir, os aspectos metodológicos referentes à presente investigação.

\section{Metodologia}

\section{Delineamento da pesquisa}

Para a presente pesquisa, foi realizado um estudo de caso com vistas a analisar a percepção dos colaboradores lotados na Célula de Desenvolvimento de Pessoas (CDP) da Gerência Regional de Educação de Petrolina sobre a QVT.

A pesquisa é também de natureza exploratória. Tendo em vista que este tipo de pesquisa proporciona uma compreensão mais abrangente acerca do assunto estudado (HAIR, 2005), buscou-se ter conhecimentos relacionados à percepção dos colaboradores da CDP acerca da QVT.

Além disso, nesta pesquisa adotou-se a perspectiva quantitativa. Para Roesch (2006) o método quantitativo enfatiza a utilização de dados padronizados que permitem ao pesquisador elaborar sumários, comparações e generalizações. Ao serem utilizados dados de natureza quantitativa, pretendeu-se analisá-los com uma amostra e generalizar os resultados quantificados com a população de 18 colaboradores. 
Id on Line Revista Multidisciplinar e de Psicoloqia

Id on Line Revista Multidisciplinar e de Psicologia

Os colaboradores-alvo (servidores e contratados) deste estudo estavam lotados especificamente na Célula de Desenvolvimento de Pessoas (CDP). O corpo funcional deste setor na GRE é composto basicamente de servidores estatutários (técnicos administrativos e professores) e alguns contratados temporariamente e conta com um total de 18 colaboradores, sendo: quatro professores efetivos, desempenhando atividades administrativas; seis assistentes administrativos educacional efetivos; três analistas em gestão educacional efetivos; cinco contratados de áreas diversas.

A seleção foi feita por amostragem probabilística - aleatória simples - e busca representar o universo da população de 18 colaboradores (servidores e contratados) que compõem os seguintes setores que funcionam na GRE de Petrolina: Unidade de Gestão da Rede (UGR), Unidade de Desenvolvimento de Ensino (UDE), Célula de Desenvolvimento de Pessoas (CDP).

\section{Métodos de Coleta de dados}

Como instrumento de coleta de dados, para este estudo de caso foi utilizado um questionário com perguntas fechadas enviado para os colaboradores através de correio eletrônico, para que o mesmo fosse respondido através da plataforma google forms.

Inspirado em Fernandes (1996), o questionário foi elaborado com base na abordagem desenvolvida pela autora, que consta de nove dimensões, que são: condições de trabalho, compensação, moral, imagem da empresa, saúde, organização do trabalho, participação, comunicação e relação chefe-subordinado. Destaca-se que os dados foram analisados quantitativamente com apoio do software Excel

Visando ser breve e de fácil entendimento pelo entrevistado e para proporcionar uma melhor compreensão por parte dos sujeitos da pesquisa, procurou-se fazer uso de linguagem simples, perguntas curtas e uma escala apenas de cinco pontos no questionário aplicado. Vale ressaltar que foram obtidas 15 respostas dos 18 colaboradores lotados no setor, ou seja, uma participação de $83 \%$ e que os dados foram coletados no mês de abril de 2016.

\section{Análise dos Dados}

\section{Perfil dos entrevistados}

Com base nos dados obtidos, observa-se que, em sua maioria, os entrevistados são do sexo feminino (87\%), na faixa etária acima de 36 anos (73\%). Em relação ao tempo de serviço prestado, 
Id on Line Revista Multidisciplinar e de Psicoloqia

Id on Line Revista Multidisciplinar e de Psicologia

47\% dos respondentes possuem de cinco a oito anos e $40 \%$ mais de nove anos, ou seja, são pessoas que não estão em início de carreira.

Quanto ao nível de instrução, a maioria possui especialização (60\%) e os demais estão em nível de graduação, evidenciando, assim, o interesse em investir em sua formação, já que as funções para as quais parte dos entrevistados foram nomeados o requisito é apenas o nível médio.

Análise do nível de satisfação e qualidade de vida com base no modelo desenvolvido por Fernandes (1996)

\section{Condições de trabalho}

Conforme demonstrado na figura 1, que trata da dimensão Condições de Trabalho, no item Iluminação Adequada, o percentual mais expressivo foi de 33\%, evidenciando uma leve insatisfação. Nos quesitos Temperatura e Limpeza, houve uma distribuição equilibrada entre os pontos da escala utilizada como método de avaliação; já em relação aos Ruídos e à Ergonomia, apenas 20\% e 7\%, respectivamente, demonstraram satisfação.

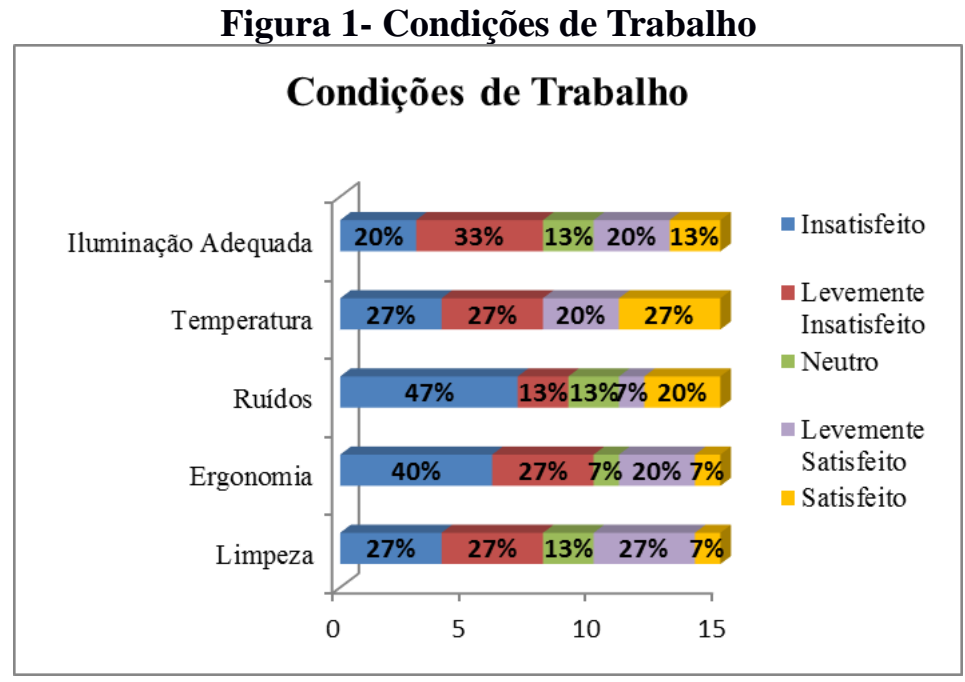

Fonte: Dados da pesquisa

Com base nos dados obtidos, percebe-se a necessidade de atentar-se para os fatores que compõem a dimensão condições do trabalho e tentar melhorá-los na perspectiva de elevar a QVT dos colaboradores em relação aos mesmos, já que nesta dimensão a média geral de satisfação é de apenas 34\%. Gil (2007) contribui com esta discussão ao dizer que a nítida separação entre o espaço de trabalho e a casa é a mais importante divisão do trabalho que surgiu como consequência da Revolução 
Id on Line Revista Multidisciplinar e de Psicologia

Id on Line Revista Multidisciplinar e de Psicologia

Industrial, fazendo com que os trabalhadores desejem ambientes de trabalhos cada vez mais agradáveis, desafiando as organizações a investir no ambiente, sob a perspectiva de atrair e manter talentos, além de melhorar a produtividade.

\section{Compensação}

Os fatores que integram a dimensão Compensação percebem-se alguns índices expressivos. No item Plano de Cargos e Carreira, 67\% dos respondentes expressaram total insatisfação. Em relação aos Benefícios, $73 \%$ dos respondentes disseram estar insatisfeitos e, no que tange aos Salários, os índices de insatisfação também são relevantes, com $60 \%$ e $27 \%$ insatisfeitos e levemente insatisfeitos, respectivamente.

Tendo em vista os resultados obtidos, visualiza-se uma situação preocupante em relação a esta dimensão, pois, a média geral de insatisfação é de $87 \%$, o que aponta a necessidade urgente de adoção de medidas que busquem atender às expectativas dos servidores, minimizando o grau de insatisfação e contribuindo para a melhoria da qualidade de vida deles.

\section{Moral}

Em relação aos resultados alcançados, $47 \%$ e $40 \%$ dos respondentes revelaram estar satisfeitos e levemente satisfeitos, respectivamente, no item Identificação com a Tarefa. No item Reconhecimento, 33\% dos avaliados manifestaram neutralidade, já no quesito Relações Interpessoais, $53 \%$ estão levemente satisfeitos. Nessa dimensão, os dados coletados não demonstraram entraves significativos, já que há uma expressiva manifestação de satisfação considerando a média geral que é de $67 \%$ e $20 \%$ na média geral ficaram neutros. Portanto, apenas $13 \%$ manifestaram insatisfação nessa dimensão, considerando a média geral.

Nesta dimensão, segundo Fernandes (1996), busca-se identificar a efetividade das ações gerenciais ligadas a aspectos psicossociais que se refletem na motivação e moral do profissional e nela é possível perceber a importância dos cargos e das tarefas dentro da estrutura organizacional da CDP. Chiavenato (2004) contribui com esta análise ao afirmar que, o cargo é visto como um dos principais geradores de expectativas e de motivação na organização.

Daí a importância da identificação dos funcionários com as tarefas que desempenham e com os cargos que ocupam, para que possam fazer uso de forma prazerosa das suas competências e habilidades enquanto executam as atividades que estão sob sua responsabilidade. 
Id on Line Revista Multidisciplinar e de Psicologia

Id on Line Revista Multidisciplinar e de Psicologia

\section{Imagem da Empresa}

Em relação à imagem da organização, pode-se notar que os resultados perpassam por todos os pontos da escala, demonstrando percepções bem divergentes tanto em relação à Imagem Externa da Organização quanto à Identificação do Servidor com a Organização. De modo geral, fica evidente um quadro a ser melhorado no que tange à QVT, já que a média geral de satisfação é de $50 \%, 17 \%$ de neutralidade e $33 \%$ de insatisfação.

Esses dados são preocupantes, pois depreende-se que, caso o funcionário não se identifique com a organização e não aprove a imagem que ela projeta para a comunidade externa e interna, os objetivos individuais e organizacionais estarão desalinhados dificultando o alcance das metas estabelecidas.

Percebe-se com isso a importância do órgão estudado trabalhar os fatores ligados a QVT, contribuindo para a satisfação do seu colaborador, o que poderá se refletir positivamente na melhoria da imagem da organização, bem como no desempenho pessoal e organizacional.

\section{Saúde}

Este item tem por objetivo analisar as ações que são realizadas pela CDP com relação à Saúde. Desse modo, foram considerados os seguintes elementos: Segurança no Trabalho, Saúde Ocupacional, Assistência para a Família do Funcionário e Assistência para o Funcionário.

Com base na figura 2, para todas as ações consideradas neste bloco do item Saúde, observa-se que os índices percentuais revelam uma média geral de 58,25\% de colaboradores insatisfeitos e que apenas $1,75 \%$ mostram-se satisfeitos. Assim, somando-se estes percentuais com a média dos itens levemente insatisfeito e levemente satisfeito, obtém-se, respectivamente, média geral de $80 \%$ de colaboradores insatisfeitos e $10 \%$ de satisfeitos.

Desse modo, verifica-se que grande parte dos servidores não está satisfeita com as ações desenvolvidas, sinalizando que não percebem preocupação da instituição com a saúde dos seus trabalhadores.

Assim, o alto índice de insatisfação sinaliza que o órgão ainda não se preocupa devidamente com a saúde de seus servidores, e, portanto, talvez não perceba a relevância do bem-estar geral e a saúde dos trabalhadores no desempenho de suas tarefas (CHIAVENATO, 2004). 
Figura 2- Saúde

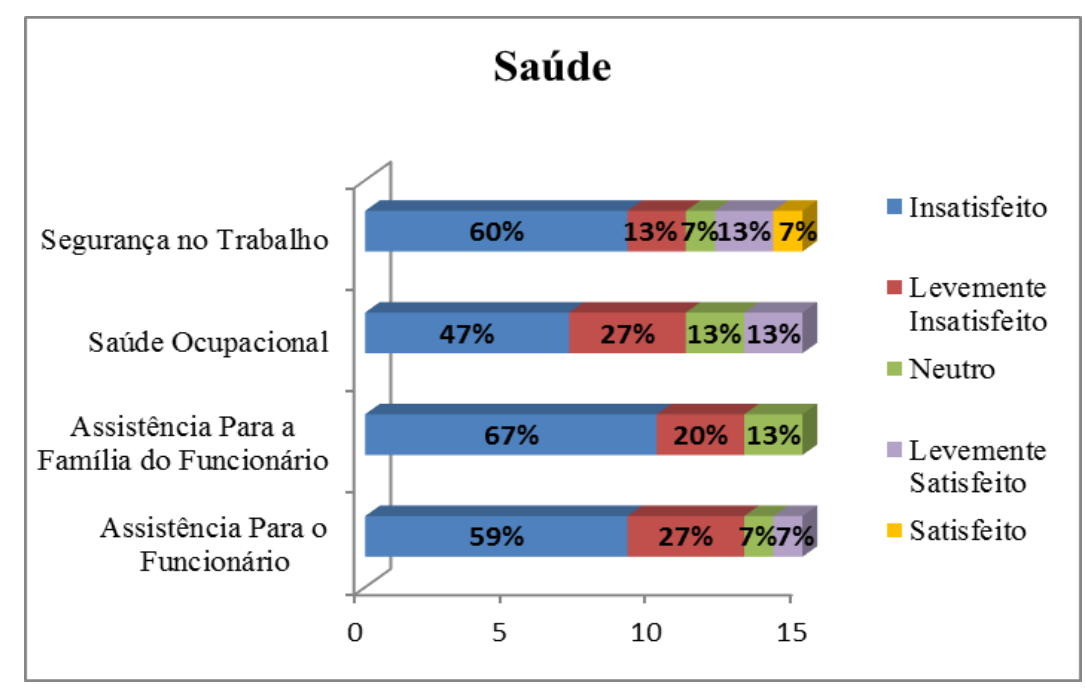

Fonte: Dados da pesquisa

\section{Organização do trabalho}

Neste item, o objetivo foi avaliar de que forma a Célula de Desenvolvimento de Pessoas-CDP da GRE de Petrolina está estruturada quanto às formas de trabalho. Assim, foram verificados os seguintes elementos: Metodologia de Trabalho, Carga de Trabalho, Ritmo de Trabalho e Variedade de Tarefas.

Observou-se que para a organização do trabalho, representada pelos itens carga e ritmo de trabalho, obteve-se 33\%, demonstrando que os servidores estão levemente satisfeitos e que $27 \%$ encontram-se satisfeitos. Ao se analisar a média geral destes itens, $60 \%$ dos colaboradores considera a carga e o ritmo de trabalho na organização satisfatório. Em termos de QVT, isso é positivo para a organização, pois os colaboradores mostram-se mais motivados. De acordo com o modelo de Hackman e Oldham (1975), as dimensões do cargo geram efeitos psicológicos que exercem influência nos resultados pessoais e de trabalho.

Ocorre também que, os dados obtidos para a carga de trabalho da CDP e o ritmo de trabalho dos seus colaboradores mostram que eles estão alinhados frente aos interesses organizacionais e individuais, corroborando Chiavenato (2004).

Entretanto, sobre a metodologia de trabalho, $34 \%$ dos entrevistados mostrou-se neutra e isso é preocupante, pois segundo Zimpeck (1990, p. 40), "a tarefa existe como um conjunto de elementos que requer o esforço humano para determinado fim". Então, se uma vez que parcela significativa dos servidores prefere não opinar, isso pode significar que eles serão indiferentes à metodologia de trabalho imposta pela CDP e parecem não visualizar isso como importante para a QVT. 
Id on Line Revista Multidisciplinar e de Psicologia

Id on Line Revista Multidisciplinar e de Psicologia

Quanto à variedade de tarefas, 27\% estão satisfeitos e 27\% levemente satisfeitos e apenas 6\% estão insatisfeitos. Por conseguinte, os percentuais expressam que os colaboradores preferem variar nas suas atividades evitando assim o trabalho repetitivo e gerando um conhecimento mais abrangente sobre as atividades que são desenvolvidas na CDP em Petrolina.

\section{Participação}

Neste item, procurou-se examinar a percepção do funcionário quanto à Oportunidade de Contribuir com Ideais Criativas, bem como Programas de Treinamento e Capacitação.

Sobre programas de treinamento e capacitação, os números revelam que $93 \%$ dos entrevistados demonstraram insatisfação. Assim, a instituição não volta atenção necessária para esses programas, dando a entender que ela espera que os seus profissionais sejam produtivos sem serem treinados. Sendo assim, pode-se afirmar que, na ótica dos respondentes, a instituição estudada ainda não segue as recomendações de Fernandes (1996), segundo a qual, oferecer treinamento possibilita que as pessoas tenham maior participação, uma vez que a inteligência dos empregados é ativada quando eles são estimulados a participarem de programas participativos, a exemplo da tomada de decisões.

Tratando sobre o envolvimento dos funcionários nas decisões, verifica-se que $46 \%$ dos entrevistados estão insatisfeitos quanto à oportunidade de contribuir com ideias criativas. Assim, observa-se que a CDP não dá oportunidade para que os seus colaboradores desenvolvam ideias criativas, visto que órgão não os reconhece como potenciais talentos. Para Nadler e Lwaler (1983), o envolvimento dos funcionários nas decisões promove uma melhoria na QVT e é justamente a situação inversa que se encontra na CDP de Petrolina. Para reverter tal situação, talvez seja necessária uma conscientização da gestão superior acerca da realização de treinamentos contínuos e que compreendam a importância de desenvolver o seu quadro pessoal, de modo que eles possam sentir-se desafiados para contribuir com ideias inovadoras.

\section{Comunicação}

Na figura 3 os dados mostraram que, para o fluxo de informações mantido entre os servidores, tem-se uma média geral de 44,33\% de servidores satisfeitos e 30,16\% insatisfeitos. Assim, os números indicam que existe um retorno positivo não apenas entre colaboradores, mas também entre estes e os seus chefes, pois no fluxo de informações entre chefe e subordinado não existem índices de insatisfação e que apenas 14\% estão levemente insatisfeitos. 
Figura 3-Comunicação

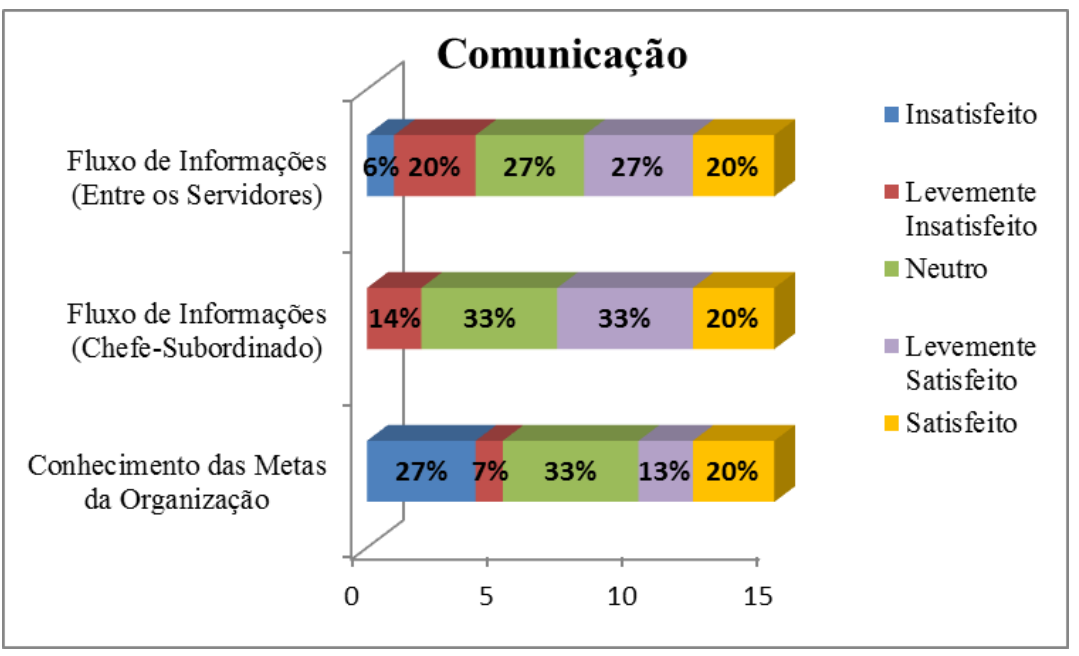

Fonte: Dados da pesquisa

Por outro lado, sobre o conhecimento de metas da organização verifica-se que $33 \%$ dos entrevistados são neutros, o que demonstra que eles não conhecem de forma efetiva os objetivos institucionais, dificultando delimitar com precisão o que a CDP pretende atingir.

\section{Relação Chefe-Subordinado}

Dada a importância da satisfação ou insatisfação dos servidores no ambiente de trabalho e o quanto isso impacta em sua motivação, buscou-se verificar a relação entre chefe-subordinado considerando os seguintes itens: Feedback, Respeito, Cordialidade, Igualdade de Tratamento e Orientação Técnica.

Figura 4- Relação Chefe-Subordinado

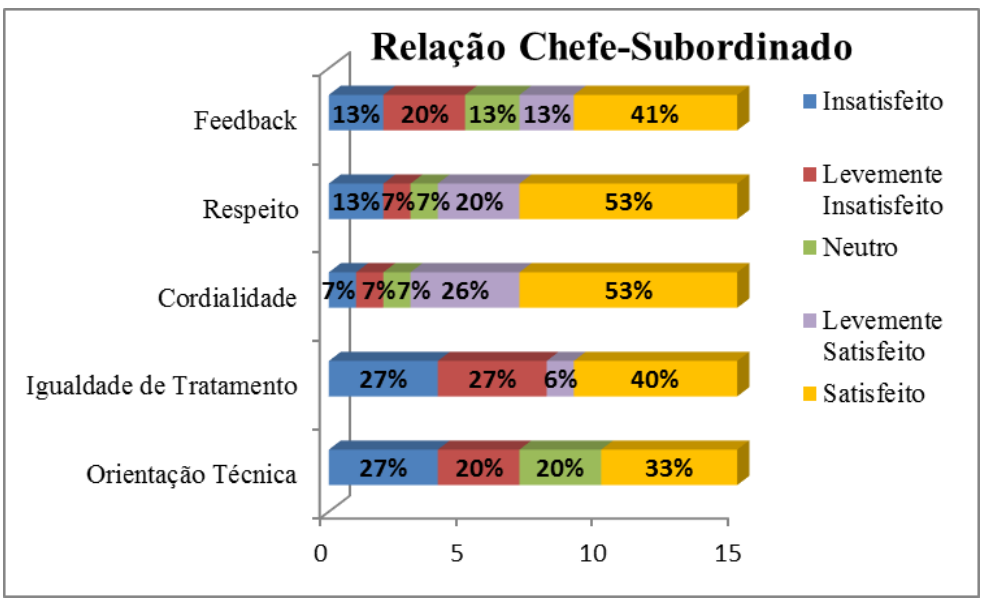

Fonte: Dados da pesquisa 
Id on Line Revista Multidisciplinar e de Psicologia

Id on Line Revista Multidisciplinar e de Psicologia

Desse modo, de acordo com a figura 4, os dados expressam que o órgão procura estabelecer bons vínculos entre chefes e subordinados, pois, de acordo com a média geral para os itens que compõem este bloco, $44 \%$ dos colaboradores estão satisfeitos e que apenas 17,4\% são insatisfeitos. Logo, para os quesitos Feedback, Respeito, Cordialidade, Igualdade de Tratamento e Orientação Técnica, por existir uma boa relação entre os colaboradores da CDP e seus superiores hierárquicos, os colaboradores recebem uma atenção desejável e, por conseguinte, mostram-se mais motivados dentro da instituição em que trabalham.

Portanto, em termos de qualidade de vida, como existe respeito e a igualdade de tratamento na CDP, pode-se afirmar que os trabalhadores sentem-se mais motivados a participar das decisões e a buscar soluções para os problemas institucionais.

Encerrada a análise e a discussão dos dados, passa-se às considerações finais deste estudo.

\section{Considerações Finais}

O presente artigo teve como objetivo geral analisar a percepção dos colaboradores lotados na Célula de Desenvolvimento de Pessoas (CDP) da Gerência Regional de Educação de Petrolina (GRE) sobre a QVT, utilizando o modelo elaborado por Fernandes (1996). Como objetivos específicos, buscou-se identificar as ações de QVT adotadas pela instituição; verificar os pontos críticos da estrutura organizacional da CDP que impactam na QVT dos seus servidores e contratados temporariamente; identificar os anseios/necessidades dos colaboradores em relação às práticas de QVT e, ainda, analisar possíveis fatores causadores de mal-estar no trabalho.

Assim, por meio da investigação, foi possível observar que a CDP não tem uma política e/ou programa de QVT elaborado e implementado. Além disso, as respostas dos entrevistados evidenciaram uma aproximação de pareceres em alguns pontos e divergências em outros. A melhoria de alguns fatores identificados como causadores de mal-estar não depende somente da gestão da GRE para mudá-los, mas de outras instâncias da estrutura hierárquica da administração pública, como é o caso da melhoria nos salários e benefícios dos servidores.

Considerando as dimensões do modelo de Fernandes (1996) adotado na pesquisa, pode-se dizer que, em relação à dimensão condições de trabalho, é necessária uma intervenção por parte da gestão nos fatores ligados a mesma, tendo em vista o baixo nível de satisfação. Já a compensação remuneratória apresentou um índice de insatisfação muito alto, demandando do Estado um olhar diferenciado no sentido de minimizar os efeitos negativos provocados pela atual situação; em relação a moral, a citada dimensão não apresentou dados preocupantes; para a imagem da organização não é possível perceber entraves que impactem tão fortemente na QVT dos servidores, no entanto, com a 
Id on Line Revista Multidisciplinar e de Psicoloqia

Id on Line Revista Multidisciplinar e de Psicologia

imagem da CDP fortalecida e bem vista pela sociedade fará com que os colaboradores sintam orgulho em fazer parte da mesma.

No item saúde, parcela considerável dos entrevistados não está satisfeita, verificando-se que o órgão não possui preocupação com a saúde dos seus colaboradores. Quanto à organização do trabalho, destaca-se uma média geral de satisfação de 53,5\% (de "levemente satisfeito" a "satisfeito") podendose afirmar que os colaboradores se sentem orgulhosos das práticas de organização do trabalho existente dentro da CDP. Na participação teve um índice muito alto de insatisfação revelando que a gestão superior precisa envolver mais as pessoas no processo de tomada de decisão, pois isso além de elevar o nível de satisfação das pessoas aumenta a produtividade da organização. Para a comunicação, os dados mostram índices de satisfação de 44,33\% (de "levemente satisfeito" a "satisfeito") quanto ao fluxo de informações. Para a relação chefe-subordinado obteve-se como média geral que $44 \%$ dos entrevistados estão satisfeitos e que apenas $17,4 \%$ insatisfeitos.

Espera-se que os resultados obtidos sirvam como base para que a CDP possa tomar decisões com relação às práticas que são adotadas pela instituição no que tange à QVT, buscando assegurar uma gestão pautada em uma atuação mais humana e preocupada com a satisfação e Qualidade de Vida dos seus colaboradores. Vale ressaltar, que o presente trabalho servirá como mais uma fonte de pesquisa que subsidiará outros trabalhos sobre QVT e principalmente aqueles com foco em organizações públicas municipais, já que a quantidade de material produzido voltado para esta área ainda é insuficiente, se comparada com a produção direcionada para as organizações em geral.

Sendo a QVT uma temática que não se esgota e dada a relevância do assunto para os indivíduos e para as organizações, é de suma importância o desenvolvimento de novas pesquisas em outras instituições, seja da esfera municipal, estadual ou federal, contribuindo assim com o desenvolvimento da região em que estão inseridas.

\section{Referências}

ANDION, C. Por uma nova interpretação das mudanças de paradigmas na administração pública. Cad. EBAPE, Rio de Janeiro, v. 10, n. 1, Mar. 2012.

AMORIM, T. G. F. N. Qualidade de vida no trabalho: preocupação também para servidores públicos?. Revista Eletrônica de Ciência Administrativa, v. 9, n. 1, p. 35-48, 2010.

ARELlanO, E. B. (2007). Práticas premiadas em qualidade de vida. In: Lombardi, T. M.; Simurro, S. A. B. e Arellano, E. B. (Eds.) Prêmio nacional de qualidade de vida: a trajetória de uma década. São Paulo: ABQV.

ARENDT, H. A condição humana. Rio de Janeiro: Forense Universitária, 2003.

BERGUE, S.T. Gestão de Pessoas em Organizações Públicas. 3. ed. Caxias do Sul: Educs, 2010. 
Id on Line Revista Multidisciplinar e de Psicoloqia

Id on Line Revista Multidisciplinar e de Psicologia

CHIAVENATO, I. Gestão de pessoas e o novo papel dos recursos humanos nas organizações. Rio de Janeiro: Elsevier, 2004.

COSTA, C. Sociologia: questões da atualidade. São Paulo: Moderna, 2010.

DUTRA, J.S. Gestão de Pessoas: modelo, processos, tendências e perspectivas. 1. ed. Barueri: Atlas, 2012.

FERNANDES, E. C. Qualidade de vida no trabalho: como medir para melhorar. Salvador: Casa da Qualidade, 1996.

FERREIRA ET AL. Gestão da Qualidade de Vida no Trabalho (QVT) no Serviço Público Federal: o descompasso entre problemas e práticas gerenciais. Psicologia: Teoria e Pesquisa. Vol. 23, n. 3, Jul-Set 2009.

FISCHER, A. L. Um resgate conceitual e histórico dos modelos de gestão de pessoas. In: FLEURY, M. T. L. (Org). As pessoas na organização. 8 ed. São Paulo: Gente, 2002.

GIL, A. C. Gestão de pessoas: enfoque nos papéis profissionais. São Paulo: Atlas, 2007.

HAIR, Joseph F. Fundamentos de métodos de pesquisa em administração. Porto Alegre: Bookman, 2005.

LIMONGI-FRANÇA, A. C. Qualidade de vida no trabalho-QVT: conceitos e práticas nas empresas da sociedade pós-industrial. 2. ed. São Paulo: Atlas, 2004.

.; ARELLANO, E. B. Qualidade de vida no trabalho. In: FLEURY, Maria Tereza Leme. (Org). As pessoas na organização. 8. ed. São Paulo: Gente, 2002.

MARRAS, J. P. Administração de recursos humanos: do operacional ao estratégico. 14. ed. São Paulo: Saraiva, 2011.

ROBBINS, S.P. et al. Comportamento Organizacional: teoria e prática no contexto brasileiro. 14 . ed. São Paulo: Pearson Prentice Hall, 2010.

ROBBINS, S. P. Comportamento Organizacional. 11. ed. São Paulo: Pearson Prentice Hall, 2005.

SÁ, M. A. D. et al. Qualidade de vida no trabalho docente - uma questão de prazer! In: ENCONTRO NACIONAL DOS PROGRAMAS DE PÓS-GRADUAÇÃO EM ADMINISTRAÇÃO, 31, 2007, Rio de Janeiro. Anais. Rio de Janeiro, ANPAD, 2007.

SILVA, M. A. D.; MARCHI, R. Saúde e qualidade de vida no trabalho. São Paulo: Best Seller, 1997.

VERGARA, S.C. Gestão de Pessoas. 10. ed. São Paulo: Atlas, 2011.

ZIMPECK, B. G. Administração de salários. São Paulo: Atlas, 1990. 
Id on Line Revista Multidisciplinar e de Psicologia

Id on Line Revista Multidisciplinar e de Psicologia

\section{Como citar este artigo (Formato ABNT):}

SOUZA, T.R.S.; SOUZA, C.S.; BARBOSA, M.A. Qualidade de Vida no Trabalho: Um estudo de caso na Célila de Desenvolvimento de Pessoas da Gerência Regional de Educação do Sertão do Médio São Francisco Id on Line Revista ultidisciplinar e de Psicologia, Julho de 2016, vol.10, n.30, Supl 2 p. 169-188. ISSN 1981-1179.

Recebido: $05 / 05 / 2016$

Aceito: $17 / 05 / 2016$ 